\title{
Highly active iron imidazolylidene catalysts for atom transfer radical polymerization
}

\author{
Janis Louie and Robert H. Grubbs* \\ The Arnold and Mabel Beckman Laboratories of Chemical Synthesis, California Institute of Technology, Pasadena, \\ CA 91125, USA. E-mail: rhg@cco.caltech.edu
}

\author{
Received (in Irvine, CA, USA) 15th May 2000, Accepted 19th June 2000 \\ Published on the Web 19th July 2000
}

Iron(II) halides possessing highly donating imidazolylidene ligands were found to be remarkably active and efficient catalysts for the atom transfer radical polymerization of styrene and methyl methacrylate.

Atom transfer radical polymerization (ATRP), a method for controlling free radical polymerizations, has recently developed into a versatile tool in polymer chemistry. ATRP is a metal mediated halide exchange process that establishes a fast and dynamic equilibrium between growing $\left(\mathrm{P}_{\mathrm{n}} \bullet\right)$ and dormant $\left(\mathrm{P}_{n}-\right.$ $\mathrm{X})$ polymer chains. This equilibrium is dramatically shifted towards favoring the dormant species giving extremely low $\left(c a \cdot 10^{-8} \mathrm{M}\right)$ radical concentrations which effectively minimizes bimolecular termination. A fast halide exchange process ensures all polymer chains grow at the same rate giving excellent control over the radical polymerization. Most reports describe the use of a combination of copper(I) halides and amine ligands as ATRP catalysts. ${ }^{1}$ However, the ability to conveniently tune catalyst reactivity has led to the emergence of other metal systems $\left(\mathrm{Ru},{ }^{2} \mathrm{Rh},{ }^{3} \mathrm{Pd},{ }^{4} \mathrm{Ni}^{5,6}\right)$ since they are capable of coordinating a wide range of ligands. Recently, attention has shifted towards iron catalyzed ATRP owing to its lower cost and similar activity to their ruthenium analogs. ${ }^{6}$

A steady effort has been directed toward designing ligands that display improved activity in ATRP, yet are still cost effective. In copper based ATRP, replacement of bipyridine ligands with alkyl amines lowers the redox potential of the copper halide catalyst and accelerates the polymerizations. ${ }^{7} \mathrm{~A}$ similar phenomenon was also observed in ruthenium and iron $6 e$ catalyzed ATRP when triphenylphosphine and bipyridine were replaced with tributylphosphine and tributylamine, respectively. Noels and coworkers reported the highly active ruthenium ring-opening metathesis polymerization (ROMP) catalyst, $\mathrm{Cl}_{2}\left(\mathrm{PCy}_{3}\right)_{2} \mathrm{Ru}=\mathrm{CHPh}$, was also active for ATRP. ${ }^{8}$ Recently, a dramatic increase in the activity of ruthenium ROMP catalysts coordinated with imidazolylidenes was observed, ${ }^{9}$ largely due to their higher Lewis-basicity. In addition to being excellent electron donating ligands that are less toxic than phosphines and amines, imidazolylidenes are attractive because they are easy to prepare and handle. These observations prompted us to explore the influence of imidazolylidenes in ATRP. Herein we report the synthesis of $\mathrm{FeX}_{2} \mathrm{~L}_{2}[\mathrm{X}=\mathrm{Cl}, \mathrm{Br}$; $\mathrm{L}=1,3$-diisopropyl4,5-dimethylimidazol-2-ylidene (Prim 3 $\left.{ }^{10}\right]$ complexes and their use as catalysts in the ATRP of styrene and methyl methacrylate (MMA). The polymerization rates rival copper based systems and yield polymers with extremely low polydispersities.

Heating a toluene solution of $\mathrm{FeX}_{2}$ and Prim 3 to $90{ }^{\circ} \mathrm{C}$ followed by slow cooling of the reaction mixture to room temperature afforded crystals of chloro-complex $\mathbf{1} \dagger$ and its bromo- analog 2 in 70-85\% yields [eqn. (1)]. The structure of $1 \mp$ was determined by X-ray crystallography and is shown in Fig. 1. To the best of our knowledge, complex 1 is the first monomeric iron halide possessing imidazolylidene ligands. ${ }^{11}$ Complex 1 adopts a distorted tetrahedral geometry with angles in the range $102.05-115.62^{\circ}$. As expected the $\mathrm{Fe}-\mathrm{C}(1)$ bond length $(2.136 \AA)$ in $\mathbf{1}$ is significantly shorter than $\mathrm{Fe}-\mathrm{P}$ bond

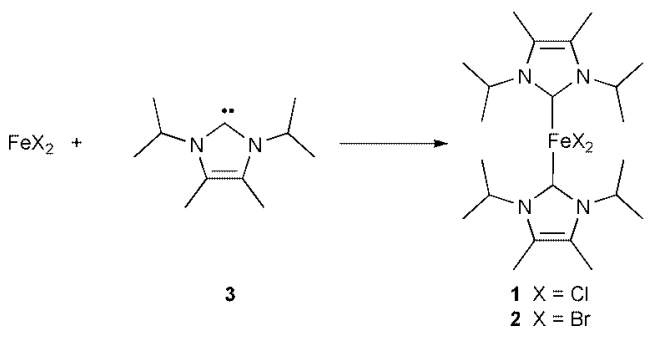

lengths $\left[2.429 \AA\right.$ in $\mathrm{FeBr}_{2}\left(\mathrm{PEt}_{3}\right)_{2}{ }^{12}$ and $2.639 \AA$ in $\left.\mathrm{FeCl}_{3}\left(\mathrm{PPh}_{3}\right)_{2}{ }^{13}\right]$ as well as $\mathrm{Fe}-\mathrm{N}$ bond lengths [2.273 $\AA$ in $\left.\mathrm{FeCl}_{3}\left(\mathrm{NMe}_{3}\right)_{2}{ }^{14}\right]$ in analogous iron based ATRP catalysts.

The homogeneous ATRP of styrene (100 equiv., 50\% v/v toluene) initiated with 1-phenylethyl bromide (1-PEBr) and 1 was monitored at $85{ }^{\circ} \mathrm{C}$ under inert atmosphere. The semilogarithmic plot of $\ln \left([\mathrm{M}]_{0} /[\mathrm{M}]\right)$ vs. time was linear, with a pseudo-first order rate constant $\left(k_{\text {obs }}\right)$ of $3.4 \times 10^{-5} \mathrm{~s}^{-1}$, and indicated that radical concentration was constant throughout the polymerization (Fig. 2). The rate of polymerization is among the highest reported for metal catalyzed ATRP in organic solvents. ${ }^{15}$ Molecular weight $\left(M_{\mathrm{n}}\right.$, determined by gel permeation chromatography relative to polystyrene standards) increased linearly over time and agreed with theoretical weights demonstrating good control [Fig. 3(a)]. Polydispersities $\left(M_{\mathrm{w}} /\right.$ $\left.M_{\mathrm{n}}\right)$ were low (ca. 1.1) and decreased with monomer conversion [Fig. 3(b)] as expected for a controlled polymerization. In addition, determination of molecular weight by end-group analysis $\left(M_{\mathrm{n}}=3400\right)$ of a low molecular weight polystyrene was in agreement with the targeted molecular weight $\left(M_{\mathrm{n}}=\right.$ 4000). Addition of the higher oxidation metal $\left(\mathrm{M}^{x+1}\right)$ to polymerizations is known to lower PDIs by shifting the equilibruim towards dormant polymer chains and lowering

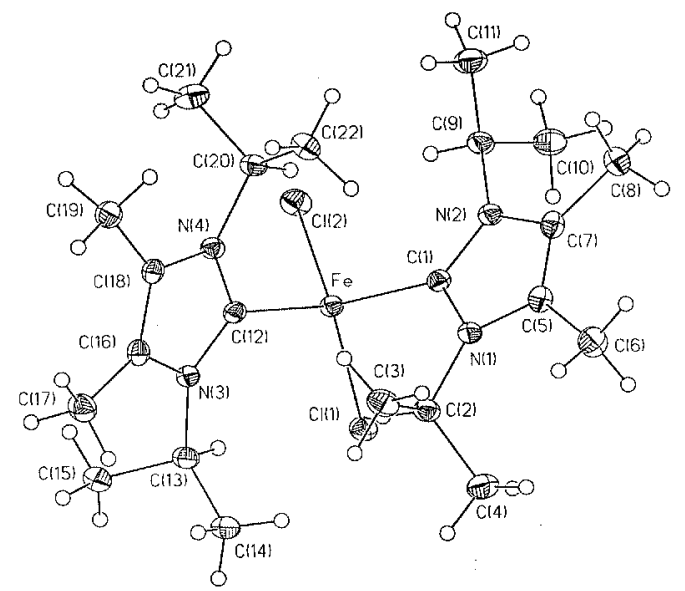

Fig. 1 Molecular structure of complex 1. Selected bond lengths $(\AA)$ and angles $\left({ }^{\circ}\right)$ : $\mathrm{Fe}-\mathrm{C}(1) 2.1363(15), \mathrm{Fe}-\mathrm{C} 1(2)$ 2.1298(16), $\mathrm{Fe}-\mathrm{Cl}(1) 2.3035(4)$ $\mathrm{Fe}-\mathrm{Cl}(2)$ 2.2976(4); C1(2)-Fe-C(1) 102.05(6), C1(2)-Fe-Cl(2) 106.85(4), $\mathrm{C}(1)-\mathrm{Fe}-\mathrm{Cl}(2) \quad 114.41(4), \quad \mathrm{C} 1(2)-\mathrm{Fe}-\mathrm{Cl}(1) \quad 115.62(4), \quad \mathrm{C}(1)-\mathrm{Fe}-\mathrm{Cl}(1)$ 104.68(4), Cl(2)-Fe-Cl(1) 112.947(17). 


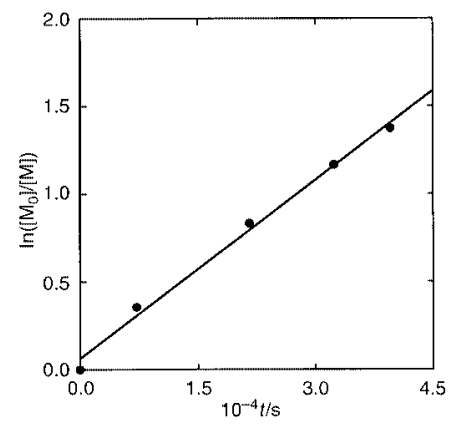

Fig. 2 First-order kinetic plot of $\ln \left([\mathrm{M}]_{0} /[\mathrm{M}]\right)$ vs. time in the polymerization of styrene $(50 \% \mathrm{v} / \mathrm{v}$, toluene $)$ at $85{ }^{\circ} \mathrm{C}\left([1]_{0}=44 \mathrm{mM},[\mathrm{PEBr}]_{0}=44 \mathrm{mM}\right.$, $\left.[\text { styrene }]_{0}=4.4 \mathrm{M}\right)$.
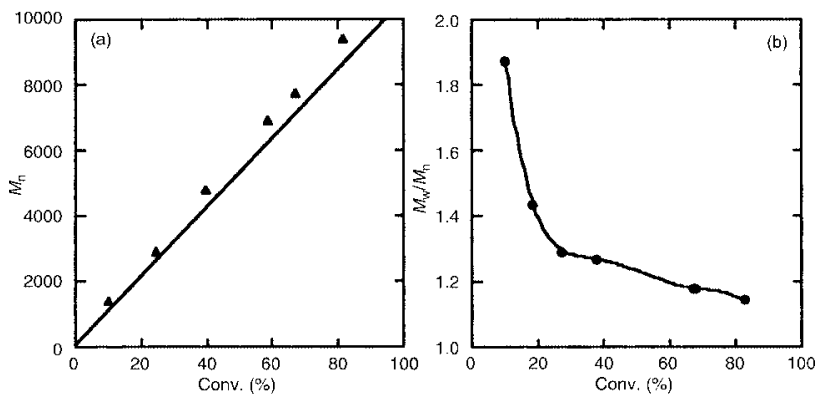

Fig. 3 Dependence of the polystyrene molecular weight (a) and polydispersity (b) on the monomer conversion at $85^{\circ} \mathrm{C}\left(\left[\mathrm{FeCl}_{2}\right]_{0}=44 \mathrm{mM},[3]_{0}\right.$ $\left.=90 \mathrm{mM},[\mathrm{PEBr}]_{0}=44 \mathrm{mM},[\text { styrene }]_{0}=4.4 \mathrm{M}\right)$.

radical concentrations. Thus, addition of 1 equiv. of $\mathrm{FeCl}_{3}$ to the reaction slowed polymerization slightly $\left(k_{\mathrm{obs}}=1.7 \times 10^{-5}\right.$ $\mathrm{s}^{-1}$ ) but afforded polymers with lower PDIs (1.05 vs. 1.14). With or without additional $\mathrm{FeCl}_{3}$, the PDIs of the resulting polymers rival those obtained by anionic polymerizations as well as other metal catalyzed ATRP systems. ${ }^{16}$

Bromo complex 2 had a higher observed rate constant $\left(k_{\mathrm{obs}}=\right.$ $\left.4.2 \times 10^{-5} \mathrm{~s}^{-1}\right)$ than chloro complex $\mathbf{1}\left(k_{\mathrm{obs}}=3.4 \times 10^{-5} \mathrm{~s}^{-1}\right)$ which may be related to the difference in the iron halide bond dissociation energies. A similar rate enhancement has also been observed in both copper and ruthenium based systems. ${ }^{17}$ Although catalysts $\mathbf{1}$ and $\mathbf{2}$ are relatively simple to synthesize, iron(II) halides can be used directly in the presence of free PriIm ligand 3 to generate the catalyst in situ. An added benefit of using Prim 3 is that it is a microcrystalline solid that is indefinitely stable under an inert atmosphere. The observed rate constant for $\mathbf{1}$ is slightly lower than when using $\mathrm{FeCl}_{2}$ and $\mathrm{Pr}^{\mathrm{i}} \mathrm{Im}$ $3\left(k_{\text {obs }}=2.7 \times 10^{-5} \mathrm{~s}^{-1}\right)$ and may be related to an induction period involving catalyst formation.

The ATRP of methyl methacrylate using complex 1, complex 2, and the complex formed in situ was also investigated. The homogeneous polymerization of MMA (100 equiv., 50\% v/v benzene) was initiated with ethyl 2-bromoisobutyrate (EBIB) and monitored at $60{ }^{\circ} \mathrm{C}$ under an inert atmosphere. Results analogous to the ATRP of styrene were observed and indicated that these catalysts are also effective in controlling the polymerization of MMA. In addition, a similar trend in observed rate constants as discussed above was observed: complex $2\left(k_{\mathrm{obs}}=1.6 \times 10^{-4} \mathrm{~s}^{-1}\right)>$ complex $\mathbf{1}\left(k_{\mathrm{obs}}=1.2 \times\right.$ $\left.10^{-4} \mathrm{~s}^{-1}\right)>\mathrm{FeCl}_{2}$ and Prim $3\left(k_{\mathrm{obs}}=8.1 \times 10^{-5} \mathrm{~s}^{-1}\right)$. Addition of $\mathrm{FeCl}_{3}$ reduced the rate of polymerization $\left(k_{\mathrm{obs}}=\right.$ $\left.3.5 \times 10^{-5} \mathrm{~s}^{-1}\right)$ but afforded polymers with lower PDIs (1.47 vs. 1.09).

Our results confirm that increased electron donacity of the ligands play an important role in the activity of ATRP catalysts. The high Lewis basicity of the imidazolylidene may lower the redox potential of the iron(II) complexes facilitating halide abstraction from dormant polymer chains. This would shift the equilibrium toward growing polymer radicals and therefore increase the rate of polymerization. Interestingly, the relatively high radical concentration does not seem to compromise the control. The increased donacity of these ligands may also stabilize the iron(III) species ${ }^{18}$ and therefore enhance the rapid exchange of halides between dormant and active polymer chain ends.

J. L. gratefully acknowledges the National Institute of Health for a Postdoctoral Fellowship. We thank Christopher W. Bielawski for helpful discussions and crystallographers Lawrence M. Henling and Michael Day.

\section{Notes and references}

$\dagger 1: \delta_{\mathrm{H}}\left(\mathrm{THF}-\mathrm{d}_{8}\right) 17.3$, 6.3. IR (KBr) 2976vs, 1632s, 1551s, 1464s, 1357s, $1290 \mathrm{w}, 1239 \mathrm{~m}, 1216 \mathrm{~m}, 1195 \mathrm{~m}, 1167 \mathrm{w}, 1137 \mathrm{~m}, 1115 \mathrm{~m}, 1071 \mathrm{w}, 905 \mathrm{w}$, $751 w, 665 w, 545 w$. Anal. Calc. for $\mathrm{FeCl}_{2} \mathrm{C}_{22} \mathrm{H}_{40} \mathrm{~N}_{4}$ : C, 54.22; H, 8.27; N, 11.50. Found: C, $53.99 ; \mathrm{H}, 8.28 ; \mathrm{N}, 11.34 \%$.

2: $\delta_{\mathrm{H}}\left(\mathrm{THF}-\mathrm{d}_{8}\right) 24.8,6.0 . \mathrm{IR}(\mathrm{KBr}) 2987 \mathrm{vs}, 1750 \mathrm{w}, 1629 \mathrm{~s}, 1557 \mathrm{~s}, 1453 \mathrm{~s}$, $1359 \mathrm{~s}, 1288 \mathrm{w}, 1237 \mathrm{~m}, 1216 \mathrm{~m}, 1194 \mathrm{~m}, 1167 \mathrm{w}, 1137 \mathrm{~m}, 1114 \mathrm{~m}, 1070 \mathrm{w}$, 904w, 884w, 750w, 665, 544. Anal. Calc. for $\mathrm{FeBr}_{2} \mathrm{C}_{22} \mathrm{H}_{40} \mathrm{~N}_{4}: \mathrm{C}, 45.86 ; \mathrm{H}$, 7.00; N, 9.72. Found: C, 45.89; H, 7.04; N, 9.52\%.

$\$$ Crystal data for $\mathrm{FeCl}_{2} \mathrm{C}_{22} \mathrm{H}_{40} \mathrm{~N}_{4} \mathbf{1}: M=487.33$, monoclinic, $a=$ 11.2022(8), $b=14.7746(10), c=15.1190(11) \AA, U=2502.3(3) \AA^{3}, T=$ $93 \mathrm{~K}$, space group $P_{1} / n, Z=4, \mu(\mathrm{Mo}-\mathrm{K})=0.832 \mathrm{~mm}^{-1}, 23927$ reflections collected, 5862 unique $\left(R_{\mathrm{int}}=0.0521\right)$ which were used in all calculations. The final $w R\left(F^{2}\right)$ was 0.0607 (all data). Single crystals of $\mathrm{FeCl}_{2} \mathrm{C}_{22} \mathrm{H}_{40} \mathrm{~N}_{4} \mathbf{1}$ were recrystallized from benzene, mounted in inert oil and transferred to the cold gas stream of the diffractometer. The structure was solved using direct methods and refined by full-matrix least-squares on $F^{2}$.

CCDC 182/1698. See http://www.rsc.org/suppdata/cc/b0/b003957h/ for crystallographic files in .cif format.

1 T. E. Patten and K. Matyjaszewski, Acc. Chem. Res., 1999, 32, 895.

2 T. Ando, M. Kato, M. Kamigaito and M. Sawamoto, Macromolecules, 1996, 29, 1070.

3 P. Lecmote, I. Draiper, P. Dubois, P. Teyssie and R. Jerome, Macromolecules, 1998, 31, 542.

4 V. Percec, B. Barboiu, A. Neumann, J. C. Ronda and M. Zhao, Macromolecules, 1996, 29, 3665.

5 (a) C. Granel, P. Dubois, R. Jerome and P. Teyssie, Macromolecules, 1996, 29, 8576; (b) H. Uegaki, Y. Kotani, M. Kamigaito and M. Sawamoto, Macromolecules, 1997, 30, 2249.

6 (a) M. Teodorescu, S. G. Gaynor and K. Matyjaszewski, Macromolecules, 2000, 33, 2335; (b) T. Ando, M. Kamigaito and M. Sawamoto, Macromolecules, 1997, 30, 4507; (c) X.-P. Chen and K.-Y. Qiu, Chem. Commun., 2000, 233; (d) Y. Kotani, M. Kamigaito and M. Sawamoto, Macromolecules, 1999, 32, 6877; (e) K. Matyjaszewski, M. Wei, J. Xia and N. E. McDermott, Macromolecules, 1997, 30, 8161.

7 (a) J. Xia, S. G. Gaynor and K. Matyjaszewski, Macromolecules, 1998, 31, 5958; (b) J. Xia and K. Matyjaszewski, Macromolecules, 1997, 30, 7697.

8 F. Simal, A. Demonceau and A. F. Noels, Angew. Chem., Int. Ed., 1999, 38, 538 .

9 C. W. Bielawski and R. H. Grubbs, Angew. Chem., Int. Ed., 2000, in press.

10 N. Kuhn and T. Kratz, Synthesis, 1993, 561.

11 (a) The crystal structure of two iron carbonyl complexes have been reported: G. Huttner and W. Gartzke, Chem. Ber., 1972, 105, 2714; (b) P. B. Hitchcock, M. F. Lappert, S. A. Thomas, A. J. Thorne, A. J. Carty and N. J. Taylor, J. Organomet. Chem., 1986, 315, 27.

12 B. S. Snyder and R. H. Holm, Inorg. Chem., 1988, 27, 2339.

13 J. D. Walker and R. Poli, Inorg. Chem., 1989, 28, 1793.

14 K. R. Millington, S. R. Wade and G. R. Willey, Inorg. Chim. Acta, 1984, 89, 185.

15 The rate of polymerization appears to be enhanced in aqueous systems: X.-S. Wang, R. A. Jackson and S. P. Armes, Macromolecules, 2000, 33, 255.

16 T. E. Patten, J. Xia, T. Abernathy and K. Matyjaszewski, Science, 1996, 272, 866.

17 (a) K. Matyjaszewski, D. A. Shipp, J.-L. Wang, T. Grimaud and T. E. Patten, Macromolecules, 1998, 31, 6836; (b) T. Ando, M. Kamigaito and M. Sawamoto, Macromolecules, 2000, 33, 2819.

18 It is known that many iron(III) complexes have low stabilities: K. B. Renkema, M. Ogasawara, W. E. Streib, J. C. Huffman and K. G. Caulton, Inorg. Chim. Acta, 1999, 317, 226. 